\title{
Determination of Curcuma longa L. (Turmeric) Leaf Extraction Conditions Using Response Surface Methodology to Optimize Extraction Yield and Antioxidant Content
}

\author{
Sera Kim ${ }^{D},{ }^{1}$ Seok-Chun Ko ${ }^{D},{ }^{2}$ Yoon-Sook Kim, ${ }^{1}$ Sang-Keun Ha ${ }^{D},{ }^{1}$ Ho-Young Park, ${ }^{1}$ \\ Yongkon Park, ${ }^{1}$ and Sang-Hoon Lee ${ }^{1}{ }^{1}$ \\ ${ }^{1}$ Korea Food Research Institute, Wanju 55365, Republic of Korea \\ ${ }^{2}$ Marine-Integrated Bionics Research Center, Pukyong National University, Busan 48513, Republic of Korea \\ Correspondence should be addressed to Sang-Hoon Lee; shnlee@kfri.re.kr
}

Received 24 June 2019; Revised 27 August 2019; Accepted 24 October 2019; Published 22 November 2019

Academic Editor: Efstathios Giaouris

Copyright (c) 2019 Sera Kim et al. This is an open access article distributed under the Creative Commons Attribution License, which permits unrestricted use, distribution, and reproduction in any medium, provided the original work is properly cited.

\begin{abstract}
Curcuma longa L. (turmeric) has been used as a functional food material, but other parts of it such as leaves are wasted as a byproduct. This work concentrated on developing turmeric leaves as a functional food material by establishing its optimal extraction condition. Response surface methodology was applied to optimize turmeric leaf extraction conditions. Turmeric leaves were pulled out with water and ethanol (10,30, and 50\%). Then, total phenolic compound content, total flavonoid content, and radical-scavenging activity of each extract were quantified to confirm the optimal extracting solvent. According to the results, water was the most efficient solvent to extract antioxidant contents such as total phenolic compounds (3.65 $\pm 0.02 \mathrm{mg} \mathrm{GAE} / \mathrm{g}$ ) and flavonoids ( $4.99 \pm 0.17 \mathrm{mg}$ QCE/g) content. Radical-scavenging activity was also higher in water extract compared with others such as DPPH $(51.10 \pm 2.29 \%), \mathrm{H}_{2} \mathrm{O}_{2}$ $(25.39 \pm 2.69 \%)$, and ABTS $(91.08 \pm 0.15 \%)$. Central composite design was applied to confirm the effect of independent variables such as temperature $\left(X_{1}\right)$ and time $\left(X_{2}\right)$ to the yield $\left(Y_{1}\right)$. After conducting experiments, the extraction condition was established as 150 min with $1: 25$ ratio at $85^{\circ} \mathrm{C}$ with a $15.58 \%$ yield. Proximate compositions of the extract were determined to suggest background data for further research. In conclusion, this study confirmed the antioxidant property of turmeric leaves and developed the optimal extraction condition of the leaves to promote its application in food industry as a new food source.
\end{abstract}

\section{Introduction}

Turmeric (Curcuma longa L.), belonging to the Zingiberaceae family, has been traditionally used as a medicinal herb, dietary spice, food source, food preservative, and a coloring agent in many Asian countries $[1,2]$. C. longa $\mathrm{L}$. is a perennial plant with a short stem and large leaves that bears ovate, pyriform, or oblong rhizomes that are brownish-yellow colored and often branched [3]. Numerous studies have been conducted using turmeric roots in many forms to investigate its characteristics, functionality, and applications $[4,5]$. In particular, several studies have reported that turmeric possesses multiple pharmacological properties such as anti-inflammatory, antioxidant, antitumor, antibacterial and anticoagulant, and antidiabetic based on its free-radical-scavenging activity [6]. These pharmacological properties of turmeric come from three major curcuminoids: curcumin, desmethoxycurcumin, and bisdemethoxycurcumin [7]. Among these curcuminoids, curcumin is the most frequently studied substance with its characteristics and functionality including inhibition of hepatic lipid accumulation, anti-inflammatory response, and cancer cell proliferation $[5,8]$. However, almost all of the studies related to turmeric are only focused on turmeric itself and its well-known functional components to demonstrate their effects. Therefore, the study using turmeric byproducts such as leaves and stem are insufficient and limited to explain their characteristics and functionality.

Actually, according to the recent reports, the wasted parts of turmeric such as the leaves and stems also have their own functionality from its curcumin and other bioactive components. Turmeric leaves also have a large volume and surface area, which gives it outstanding merit for industrial 
applications as a plentiful food source [9]. Some studies have investigated the physiochemical characteristics of the turmeric leaf extract to demonstrate its functional effects such as whitening, cosmeceutical, skin immunity, anti-inflammation, and antioxidant activities [10]. These effects mainly come from curcumin, total phenolic compounds, and the flavonoids in turmeric leaves [6]. In spite of its functional properties, turmeric leaves are not used in industrial fields because of lack in safety and legal background. For these reasons, turmeric leaves are only used as stock feed in some parts and disposed as a waste with vast disposal costs [9]. Therefore, this study focused on the turmeric leaves' optimal extract condition and its functionality to develop turmeric leaves as a functional food material.

Turmeric leaves were extracted as a food material using response surface methodology (RSM) to optimize its extraction condition by evaluating the effect of several process variables and their interactions on response variables [11]. According to the Nor Fadzillah Mohd Mokhtar's study [12], RSM is a collection of mathematical and statistical technique being widely used in many fields for technological applications to optimize the experimental conditions. RSM is also a useful technique to maximize or minimize independent variables as it evaluates the effects of multiple factors and the respective interactions on one or more response variables simultaneously. Moreover, RSM not only serves as a visual aid to have a clearer picture about the effects of various factors on extraction but also helps to locate the region where the extraction is optimized [12]. For these reasons, many researchers have used the response surface methodology to model and optimize the biochemical and biotechnological processes related to food systems such as extracting functional components from buckwheat [13] and Corni fructus [14]. Therefore, this study has established the optimal extract conditions of turmeric leaves using a central composite design derived from RSM.

Although several studies have already explored the efficacy and characteristic of turmeric leaves in some parts, their functional and safety backgrounds still remain limited. In this regard, it is necessary to examine turmeric leaves' bioactive compounds and its functionality as a potential food source. Therefore, this study encloses the functional property and the optimum extraction condition of turmeric leaves to suggest fundamental data for industrial applications.

\section{Materials and Methods}

2.1. Plant Materials. Turmeric leaves were provided from Jindoulgeum corp. (Jindo-gun, Jeollanamdo, Korea). Fresh turmeric leaves were harvested between September and November and washed several times to eliminate soil and impurity. Then, the leaves were hot-air dried at $50^{\circ} \mathrm{C}$ for $24 \mathrm{hr}$ using a convection oven for storage and further extraction. After that, the dried leaves were ground as powder and stored at room temperature.

2.2. Reagents and Chemicals. This study conducted antioxidant content and activity measuring assays to investigate the effect of the turmeric leaf extract. 10\% sodium carbonate solution, Folin-Ciocalteu reagent (Sigma-Aldrich, Germany), aluminum chloride solution, $1 \mathrm{M}$ potassium acetate solution, methanol, gallic acid, and quercetin (SigmaAldrich, Germany) standard solution were used to measure antioxidant content such as total phenolic compounds and flavonoids. Likewise, DPPH (Sigma-Aldrich, Germany) solution, $0.1 \mathrm{M}$ phosphate buffer ( $\mathrm{pH} 5.0$ ), hydrogen peroxide solution (Sigma-Aldrich, Germany), $7 \mathrm{mM}$ ABTS (Sigma-Aldrich, Germany), ammonium solution, $2.45 \mathrm{mM}$ potassium persulfate (Sigma-Aldrich, Germany), $50 \mathrm{mM}$

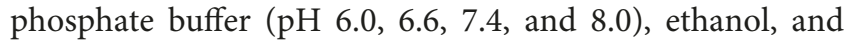
trolox (Sigma-Aldrich, Germany) standard solution were used to confirm antioxidant activity of the extract.

2.3. Solvent and Extraction Ratio. To find the most compatible solvent for turmeric leaf extraction, water and three different concentrations of ethanol $(10,30$, and $50 \%)$ were tested in this study. Turmeric leaf powder was transferred into glass vials, and each solvent was added up to $20 \mathrm{~mL}$ for extraction. These mixtures were shaken and extracted for 24 hours at room temperature. Then, each supernatant was withdrawn and filtered using the $0.45 \mu \mathrm{m}$ PVDF filter. All tests were performed within a week in triplicates.

To determine optimal extraction ratio of turmeric leaves, dried leaf powder was transferred into the glass vial with each specific gram, and water was added up to $20 \mathrm{~mL}$ to meet the extraction ratio $1: 10,15,20,25$, and 30 . The mixtures were extracted using the reflux condenser at constant temperature and time conditions to set up the appropriate extraction ratio. The supernatants were collected and filtered with a $0.45 \mu \mathrm{m}$ PVDF filter. Then, the final volume of the recollected extract was measured to calculate extraction yield (\%). Nonvolatile solids of the extract were calculated from moisture content measured by using a moisture analyzer (Sartorius, Germany).

\subsection{Determination of Antioxidant Content}

2.4.1. Total Phenolic Compounds (TPC). Total phenolic compound content was determined by the Folin-Ciocalteu method [15]. To measure total phenolic content, $0.5 \mathrm{~mL}$ of the turmeric leaf extract was mixed with $0.3 \mathrm{~mL}$ of distilled water. Then, $0.75 \mathrm{~mL}$ of $10 \%$ sodium carbonate solution was added and incubated for $3 \mathrm{~min}$. After that, $0.95 \mathrm{~mL}$ of distilled water and $0.25 \mathrm{~mL}$ of Folin-Ciocalteu reagent (Sigma Chemical, St. Louis, MO) were added to the mixture and incubated for another $30 \mathrm{~min}$ at room temperature. Absorbance was measured at a wavelength of $750 \mathrm{~nm}$. The result was expressed as $\mathrm{mg}$ of gallic acid (mg GAE/g) based on the gallic acid standard curve.

2.4.2. Total Flavonoid Content (TFC). Total flavonoid content was determined by the aluminum chloride colorimetric method $[15,16]$. To measure the total flavonoid content, $0.5 \mathrm{~mL}$ of the turmeric leaf extract was mixed with $1.5 \mathrm{~mL}$ of methanol, $2.8 \mathrm{~mL}$ of distilled water, and $0.3 \mathrm{~mL}$ of 
$3 \%$ sodium nitrite. After reaction, $0.1 \mathrm{~mL}$ of $10 \%$ aluminum chloride and $0.1 \mathrm{~mL}$ of $1 \mathrm{M}$ potassium acetate were added and incubated for $30 \mathrm{~min}$ at room temperature. Then, absorbance was measured at a wavelength of $415 \mathrm{~nm}$. The result was expressed as mg of quercetin (mg QCE/g) based on the quercetin standard curve.

\subsection{Determination of Antioxidant Activity}

2.5.1. DPPH Radical-Scavenging Activity. Antioxidant activity of the extracts was determined by 1,1-diphenyl-2picrylhydrazyl (DPPH) assay. DPPH radical-scavenging activity was measured following Soo-Jin Heo methods [15]. In brief, $0.1 \mathrm{~mL}$ of the turmeric leaf extract was added to $0.4 \mathrm{mM}$ DPPH solution and incubated for $30 \mathrm{~min}$. After reaction, absorbance was measured at wavelength $516 \mathrm{~nm}$ using Microplate Reader M2 (Molecular Devices, CA, USA). Then, DPPH radical-scavenging activity was calculated from the inhibition rate (\%) compared with that of sample blank.

2.5.2. ABTS Radical-Scavenging Activity. ABTS radicalscavenging activity was measured following Lin Zheng methods [17]. To generate ABTS, 7 mM ABTS stock solution was mixed with $2.45 \mathrm{mM}$ potassium persulfate and incubated for $12 \mathrm{hr}$ at room temperature until the reaction was complete. Then, $\mathrm{ABTS}^{+}$solution and the turmeric leaf extract were diluted with $50 \mathrm{mM}$ phosphate buffer. Then, $0.15 \mathrm{~mL}$ of diluted ABTS solution and $0.5 \mathrm{~mL}$ of the extract was dispensed to 96 well plates. Absorbance was measured immediately at a wavelength of $734 \mathrm{~nm}$ from 1, 30, and $60 \mathrm{~min}$ using Microplate Reader M2 (Molecular Devices, CA, USA). To measure the value of sample blank, ABTS was diluted with PBS to achieve $0.70 \pm 0.02$ at a wavelength of $734 \mathrm{~nm}$. ABTS radical-scavenging activity (\%) was calculated with the trolox standard curve $(\mu \mathrm{mTE} / \mathrm{mol})$ as an antioxidant standard.

\subsubsection{Hydrogen Peroxide-Scavenging Activity. Hydrogen} peroxide $\left(\mathrm{H}_{2} \mathrm{O}_{2}\right)$ radical-scavenging activity was measured following Soo-Jin Heo methods [15]. $0.1 \mathrm{~mL}$ of $0.1 \mathrm{M}$ phosphate buffer $(\mathrm{pH} \mathrm{5.0)}$ and that of the turmeric leaf extract was mixed and dispensed to 96 -well plate. Then, $0.02 \mathrm{~mL}$ of hydrogen peroxide was added to each well and incubated at $37^{\circ} \mathrm{C}$ for $5 \mathrm{~min}$. After reaction, $0.03 \mathrm{~mL}$ of $1.25 \mathrm{mM} \mathrm{ABTS}$ and that of peroxidase (unit $/ \mathrm{mL}$ ) was added and incubated at $37^{\circ} \mathrm{C}$ temperature for another $10 \mathrm{~min}$. Absorbance was measured at a wavelength of $405 \mathrm{~nm}$ using Microplate Reader M2 (Molecular Devices, CA, USA). Radical-scavenging activity of each sample was calculated from the inhibition rate (\%).

2.6. Response Surface Methodology (RSM). Response surface methodology (RSM) technique was applied to optimize the efficacy of turmeric leaf extraction. Turmeric leaves were extracted with water in a previously confirmed extraction ratio $(1: 25)$ to obtain the highest extraction yield (\%). Central composite design (CCD) was used to fit the response surface model and to confirm the relationship between response factors and the variables. The response variables such as temperature $\left(X_{1},{ }^{\circ} \mathrm{C}\right)$ and time $\left(X_{2}, \min \right)$ were encoded to three stages as $-1,0$, and 1 , and independent variables $\left(X_{\mathrm{n}}\right)$ were divided into 11 sections based on the CCD. The dependent variable $\left(Y_{n}\right)$ which was influenced by independent variables was determined as the extraction yield $\left(Y_{1}, \%\right)$. Moisture content of the filtered supernatants was measured using moisture analyzer (Sartorius, Germany) at $130^{\circ} \mathrm{C}$ in triplicates. Then, the polynomials were utilized to obtain the most reliable models where the additional coefficient estimates were significant. The final regression model of the relationship between the responses and the two independent variables for yield (\%) was expressed in the quadratic polynomial equation:

$$
Y=\beta_{0}+\sum_{i=1}^{2} \beta_{i} x_{i}+\sum_{i=1}^{2} \beta_{i i} x_{i}^{2}+\sum_{i=1}^{1} \sum_{j=i+1}^{2} \beta_{i j} x_{i} x_{j} .
$$

To verify the predictive value of the model, the optimal condition at the maximum yield (\%) was determined with the repeated extraction test. The precision of the fitted model was verified by comparing the predicted value of the experiment in triplicates.

2.7. Determination of Proximate Composition. To measure proximate composition, turmeric leaves were extracted under optimal extraction conditions. Proximate composition of dried turmeric and the turmeric leaf extract was analyzed following the Association of Official Analytical Chemists (AOAC) methods [18]. Carbohydrate, crude protein, crude fat, crude ash, fiber, and moisture contents were analyzed using the same origin sample in constant analytic condition. Carbohydrate content was calculated by subtracting all measured values of moisture, crude ash, crude protein, and crude fat from 100 percent [19]. Crude protein was measured following the micro-Kiel Dahl analytic method, and crude fat was measured following the Soxhlet method using petroleum ether as extraction solvent. Crude ash was measured by incinerating samples in muffle at $550^{\circ} \mathrm{C}$ until constant weight. Moisture content was determined by the gravimetric method at $105^{\circ} \mathrm{C}$ until constant weight. Total dietary fiber content was measured using the enzyme-gravimetric method [18].

2.8. Statistical Analysis. All data were presented as mean$\mathrm{s} \pm$ standard deviation. Statistical analysis was done using Graphpad prism software version 8.0. One-way ANOVA was used to test whether there was a significant difference in extraction yield among the supernatants extracted with different conditions. A significant difference was calculated at the level of $p$ value $<0.05$ using Tukey's regression test. The results of the extraction yield were analyzed using DesignExpert $^{\circledR}$ Version 11 software. The regressions to represent the responses were evaluated in terms of $R$-square values and the significance of their $F$ values.

\section{Results}

3.1. Antioxidant Content. Total phenolic compound content (TPC) of the turmeric leaf extracts was quantified based on 
the linear equation obtained from gallic acid standard $\left(R^{2}=0.991\right)$ and was plotted at $0.02,0.04,0.06,0.08$, and $0.10 \mathrm{mg} / \mathrm{mL}$ concentration. Thus, the TPC value was expressed as gallic acid equivalent (mg GAE/g). TPC measurement was recorded at a wavelength of $725 \mathrm{~nm}$ and carried out triplicates. According to the calculated data, the TPC value (mg GAE/g) of the water extract was $2.741 \pm 0.099$ and that of the ethanol extracts was $2.552 \pm 0.464(10 \%$ ethanol), $2.106 \pm 0.370$ (30\% ethanol), and $1.628 \pm 0.271$ ( $50 \%$ ethanol), respectively. This means that water is the best solvent to extract antioxidant content from turmeric leaves. Total flavonoid content (TFC) of the turmeric leaf extracts was calculated based on the linear equation obtained from quercetin standard $\left(R^{2}=0.998\right)$. The TFC value was expressed as quercetin equivalent ( $\mathrm{mg} \mathrm{QCE} / \mathrm{g}$ ). According to the experimental data, the TFC value (mg QCE/g) of the water extract was $4.78 \pm 0.01$ and that of the ethanol extracts was $3.58 \pm 0.01$ ( $10 \%$ ethanol), $1.73 \pm 0.01$ ( $30 \%$ ethanol), and $1.61 \pm 0.01$ ( $50 \%$ ethanol), respectively. These results show that water is the most suitable solvent to extract antioxidant contents in turmeric leaves (Figure 1). Therefore, further extraction to confirm the optimal extract condition of turmeric leaves was proceeded by water as a solvent.

3.2. Antioxidant Activity. In this study, $\mathrm{DPPH}, \mathrm{H}_{2} \mathrm{O}_{2}$, and ABTS radical-scavenging activity were measured to identify antioxidant activity of all turmeric leaf extracts. DPPH radical-scavenging activity (\%) of all extracts was $51.10 \pm 2.29$ (water extract), $51.41 \pm 0.16$ (10\% ethanol extract), $23.46 \pm 0.11$ (30\% ethanol extract), and $15.40 \pm 0.83$ (50\% ethanol extract). $\mathrm{H}_{2} \mathrm{O}_{2}$ radical-scavenging activity (\%) of all extracts was $25.39 \pm 2.69$ (water extract), $25.87 \pm 0.49$ (10\% ethanol extract), $23.11 \pm 2.49$ (30\% ethanol extract), and $22.13 \pm 0.51$ ( $50 \%$ ethanol extract). ABTS radical-scavenging activity (\%) of all extracts was $91.08 \pm 0.15$ (water extract), $87.52 \pm 1.10$ ( $10 \%$ ethanol extract), $80.87 \pm 0.49$ (30\% ethanol extract), and $64.64 \pm 1.46(50 \%$ ethanol extract), respectively. Summing up with these data, this study concluded that water is the most suitable solvent to enhance radical-scavenging activity of turmeric leaves (Figure 2).

3.3. Predicted Model Fitting and Statistical Analysis. To apply the optimal conditions to turmeric leaf extraction, a solvent ratio was preferentially set up. After extracting with reflux condenser, the volume of each extract was quantified to calibrate moisture content of the extract. The moisture content $(\% M)$ was measured to calculate the extraction yield (\%). The moisture content $(\% M)$ from the extract was as follows: 98.42 (1:10), 99.06 (1:15), 99.29 (1:20), 99.40 (1: $25)$, and $99.55(1: 30)$. Then, the yield (\%) was converted from the data as follows in order: 7.15, 10.25, 10.93, 12.09, and 12.09. According to the computed yield (\%), extraction ratio was set up as $1: 25$ (Figure 3).

Response surface methodology (RSM) is a technique to process optimization by establishing a predicting model. In this study, turmeric leaves were extracted with water and ethanol to establish optimal extraction conditions from the central composite design (CCD, Table 1). According to
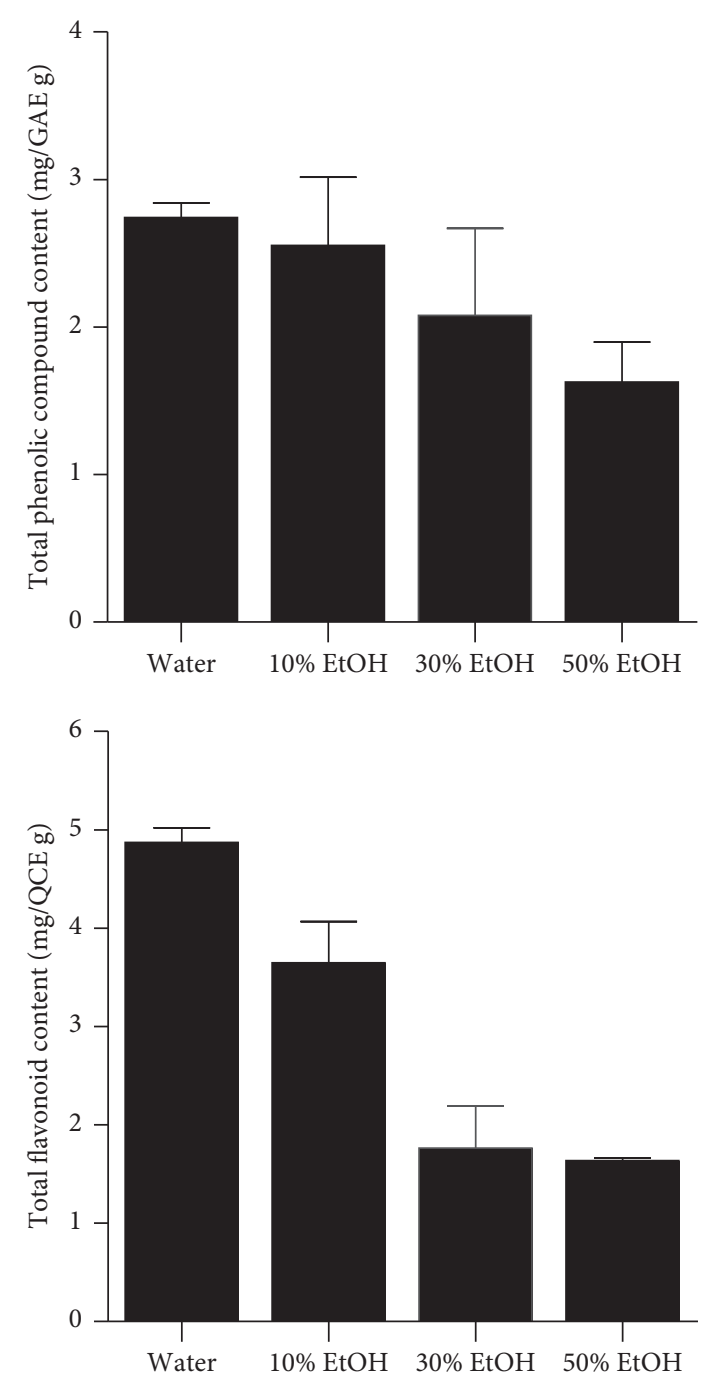

Figure 1: Total phenolic compound and flavonoid content of the turmeric leaf extracts were measured to identify antioxidant content of the turmeric leaf extracts. Turmeric leaves were extracted with different solvents to confirm the extracting solvent for the optimal antioxidant content. The extraction solvents were water and $10 \%, 30 \%$, and $50 \%$ ethanol. The experimental data were measured in triplicates. The one-way ANOVA analysis was applied with Tukey's post hoc analysis. Each data shown in this figure were expressed as mean \pm SD in $95 \%$ significance. ${ }^{*} p$ value $<0.05$.

CCD, 11 experimental sections were run for each response value. Through the result, the extraction yield (\%) was confirmed as 15.58 with the optimal extraction conditions, shown as $150 \mathrm{~min}, 85^{\circ} \mathrm{C}$, and $1: 25$ ratio. The final regression model of the relationship between responses and the two tested variables yield is presented below as the quadratic polynomial equation (Figures $4-6$ ):

$$
\begin{aligned}
\operatorname{yield}\left(\%, Y_{1}\right)= & 7.669+0.0730 x_{1}+0.04521 x_{2} \\
& -0.000018 x_{1}^{2}-0.000064 x_{2}^{2}-0.000278 x_{1} x_{2}
\end{aligned}
$$

The fitted equation shows a coefficient $\left(R^{2}\right)$ of 0.9887 , revealing that $98.87 \%$ of variance could be explained by the 

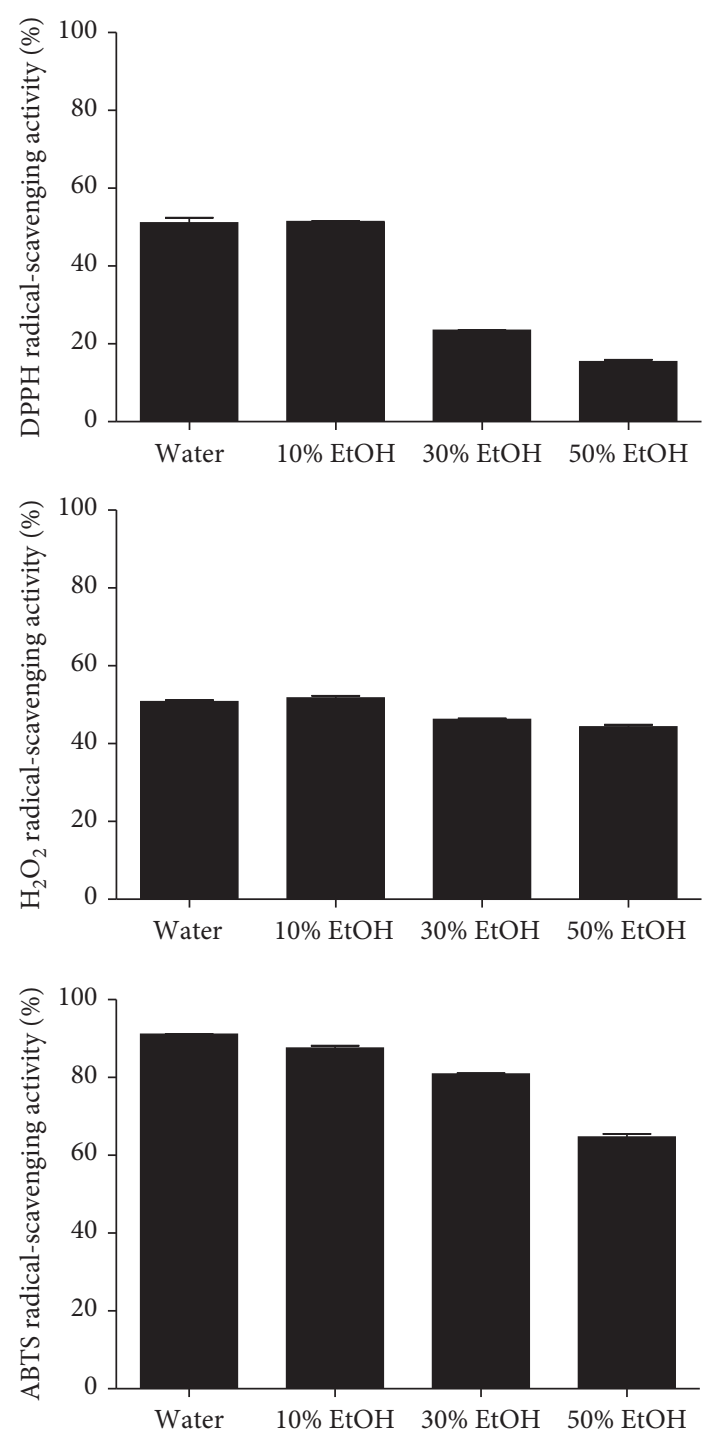

FIgURE 2: DPPH, $\mathrm{H}_{2} \mathrm{O}_{2}$, and ABTS radical-scavenging activity of the turmeric leaf extracts were measured to confirm the antioxidant effect of the turmeric leaf extracts. Turmeric leaves were extracted with different solvents to confirm the extracting solvent. The leaves were extracted with water and $10 \%, 30 \%$, and $50 \%$ ethanol. The experiment data were measured in triplicates. The one-way ANOVA analysis was applied with Tukey's post hoc analysis. Each data shown in this figure were expressed as mean \pm SD in $95 \%$ significance. ${ }^{*} p$ value $<0.05$.

model [20]. The points in Figure 3 are in a linear pattern, reflecting that normal distribution was an appropriate model for this data. Statistical significance of the model was acquired from the $F$ and $P$ values, and the ANOVA results are shown in Table 2. Obviously, the two variables were significant, and two interaction coefficients $\left(X_{1}\right.$ and $\left.X_{2}\right)$ were significant $(P<0.001)$. The "lack of fit" of the model was statistically insignificant $(P=0.339)$. To validate this prediction model, additional extractions were conducted and resulted in as 15.57 and 15.565 extraction yield (\%) with $95 \%$ significance. These results confirmed that the model is appropriate to extract turmeric leaves with its optimal extraction conditions.

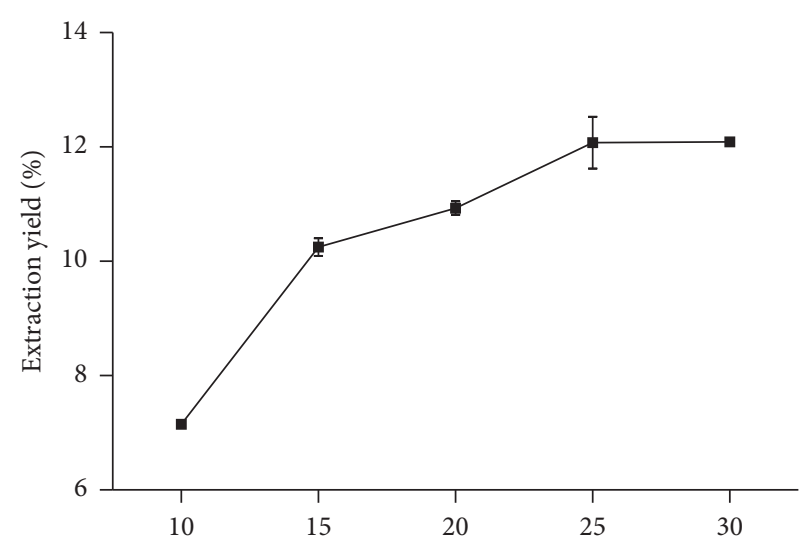

Figure 3: Extraction yield (\%) of dried turmeric leaves in different solvent ratios. The moisture content of the turmeric leaf extract in different solvent ratio groups was measured to select the most acceptable extraction ratio for the further experiment. All experimental data were measured in triplicates. The optimum solvent ratio was $12.09 \%$ in $1: 25$ extraction ratio.

\subsection{Proximate Composition of Dried Turmeric Leaves and the} Leaf Extract. The proximate composition of dried turmeric leaves was determined to support its nutritional background (Table 3). According to the analysis results with turmeric leaves, the proximate composition per dried turmeric leaves $100 \mathrm{~g}$ was $43.3 \mathrm{~g}$ carbohydrate, $6.0 \mathrm{~g}$ crude protein, $0.5 \mathrm{~g}$ crude fat, $9.4 \mathrm{~g}$ crude ash, $34.5 \mathrm{~g}$ total fiber, and $6.3 \mathrm{~g}$ moisture. The proximate composition for turmeric root refers to the result from Taoheed [21]; the proximate composition per $100 \mathrm{~g}$ was approximately $16.4 \mathrm{~g}$ carbohydrate, $1.8 \mathrm{~g}$ crude protein, $0.8 \mathrm{~g}$ crude fat, $3.0 \mathrm{~g}$ crude ash, $2.0 \mathrm{~g}$ total fiber, and $76.0 \mathrm{~g}$ moisture. Comparing proximate composition of dried turmeric leaves with the turmeric root, the content of carbohydrate and crude protein in dried turmeric leaves was slightly higher than that of turmeric root. The proximate composition per $100 \mathrm{~g}$ of the leaf extract was $2.6 \mathrm{~g}$ carbohydrate, $1.2 \mathrm{~g}$ crude protein, $0.3 \mathrm{~g}$ crude fat, $3.7 \mathrm{~g}$ crude ash, $1.2 \mathrm{~g}$ total fiber, and $91.0 \mathrm{~g}$ moisture.

\section{Discussion}

This study focused on the optimal extraction conditions and the antioxidant properties of turmeric leaf to develop it as a food source. Turmeric leaves' total production is 30-40 tons per 10 because of the plant's massive volume and surface area, which makes turmeric leaves a plentiful resource. Furthermore, the turmeric leaf extract shows potential as a functional food source from its antioxidant components such as total phenolic compound and flavonoid that enhance radical-scavenging activity. In particular, the turmeric leaf water extract had high total phenolic compound $(2.741 \pm 0.099 \mathrm{mg} \mathrm{GAE} / \mathrm{g})$ and flavonoid $(4.776 \pm 0.010 \mathrm{mg}$ QCE/g) content. Comparing these results with other studies, extracting turmeric leaves with various solvents, there is a slight difference between extraction solvents related to the antioxidant content. Several studies were conducted to optimize extract conditions of turmeric leaves with various solvents such as water and ethanol. According to the study 
TABLE 1: Central composite design matrix of two test variables in coded values and observed responses from 11 extraction conditions for the extraction of turmeric leaves.

\begin{tabular}{lcccc}
\hline Run order & Type & Temperature, $X_{1}\left({ }^{\circ} \mathrm{C}\right)$ & Time, $X_{2}(\mathrm{~min})$ & Yield, $Y_{1}(\%)$ \\
\hline 1 & Factorial & 40.000 & 60.000 \\
2 & Factorial & 100.000 & 60.000 & 12.4 \\
3 & Factorial & 40.000 & 240.000 & 15.6 \\
4 & Factorial & 100.000 & 240.000 & 150.000 \\
5 & Star & 40.000 & 150.000 & 15.0 \\
6 & Star & 100.000 & 60.000 & 14.3 \\
7 & Star & 70.000 & 240.000 & 16.1 \\
8 & Star & 70.000 & 150.000 & 14.0 \\
9 & Center & 70.000 & 150.000 & 15.4 \\
10 & Center & 70.000 & 150.000 & 15.0 \\
11 & Center & 70.000 & & 15.0 \\
\hline
\end{tabular}

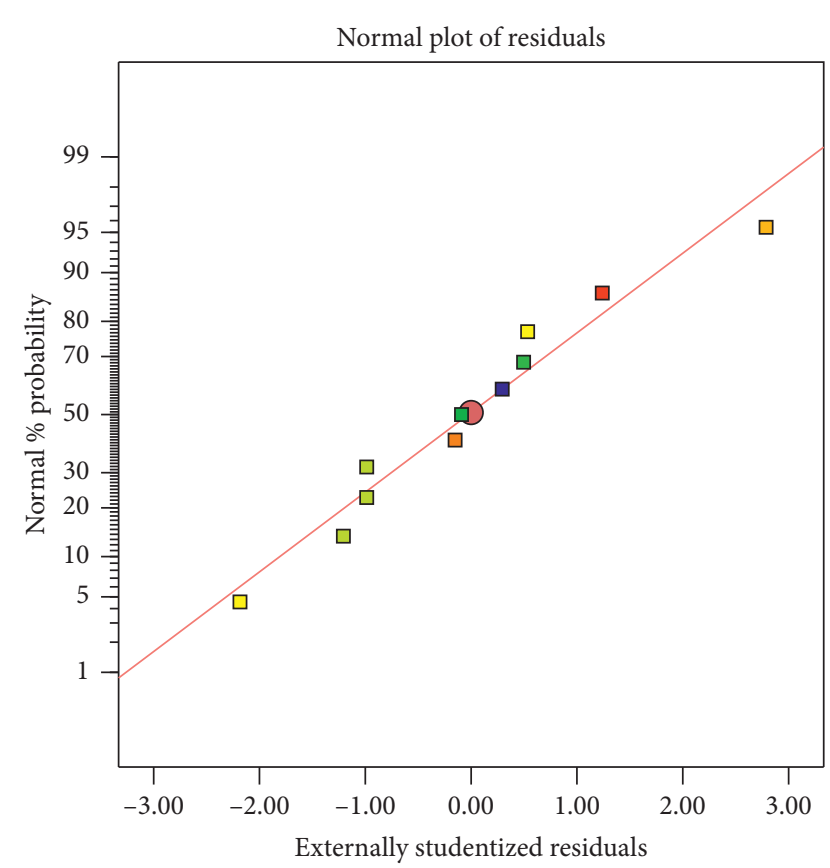

FIGURE 4: Correlation of calculated turmeric leaves with experimentally extracted turmeric leaves.

result from Choi and Lee [9], 70\% ethanol extraction showed high total phenolic compounds $(283.56 \mu \mathrm{g} / \mathrm{mg})$ compared to water extraction $(282.92 \mu \mathrm{g} / \mathrm{mg})$ and total flavonoids were also high with $70 \%$ ethanol $(106.87 \mu \mathrm{g} / \mathrm{mg})$ compared to water extraction $(95.68 \mu \mathrm{g} / \mathrm{mg})$. According to the study result from Do [22], the extraction yield (\%) decreased as solvent ethanol ratio increased from $50 \%$ aqueous ethanol to $100 \%$ ethanol. However, total phenolic compound and flavonoid content increased according to the ethanol concentration in solvent. Therefore, the best extracting solvent can be varied depending on the extraction purpose and target parameter.

This study investigated the conditions to enhance the antioxidant content of the leaf extract by altering the extraction solvent (water and ethanol) ratio $(1: 10,15,20,25$, and 30). According to the results, there is no significant difference between dried turmeric leaves extracted with water at the $1: 25$ and $1: 30$ ratio. Both extracts showed the

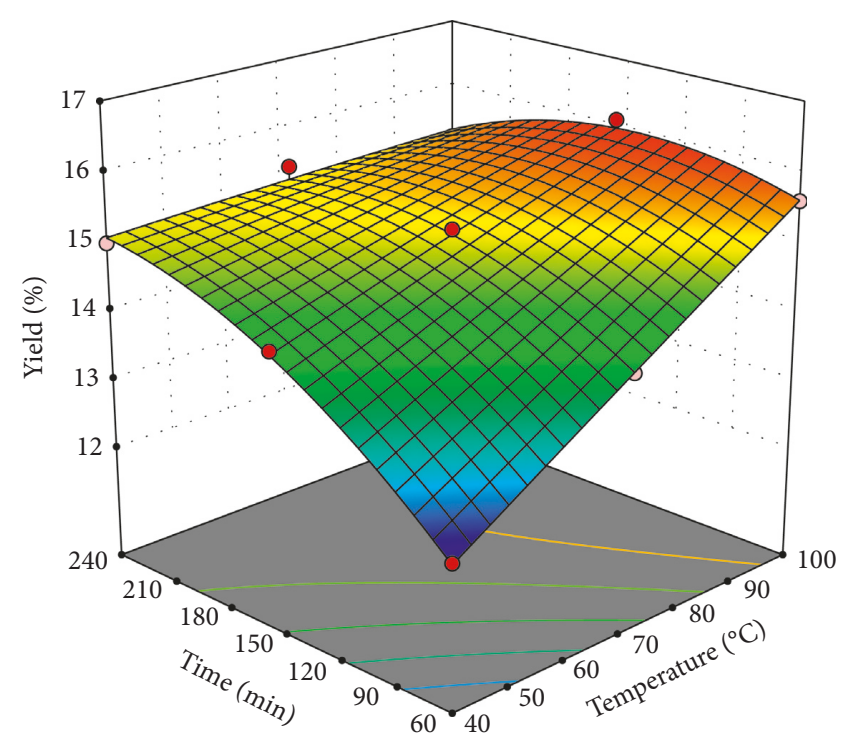

FIgURE 5: Response surface plot for the yield $\left(\%, Y_{1}\right)$ of the turmeric leaf extract at a constant value comparing extraction temperature $\left({ }^{\circ} \mathrm{C}, X_{1}\right)$ and time (min, $\left.X_{2}\right)$. The optimum yield (\%) of the turmeric leaf extract from CCD was 15.58 with the extract condition, $150 \mathrm{~min}$ (time), $85^{\circ} \mathrm{C}$ (temperature), and $1: 25$ (ratio).

highest levels of extraction ratio, and a final extraction ratio was set up to $1: 25$ in accordance with the experimental data.

The study results show that the turmeric leaf water extract exhibited the highest DPPH $(51.41 \pm 0.16), \mathrm{H}_{2} \mathrm{O}_{2}$ $(25.39 \pm 2.69)$, and ABTS $(91.08 \pm 0.15)$ radical-scavenging activity (\%) compared to the different ethanol extracts (10, 30 , and $50 \%$ ); its antioxidant activities were also proportionally increased in the water extract. Comparing these results with the study developing turmeric leaves extraction conditions [9], turmeric leaf ethanol extract $(1 \mathrm{mg} / \mathrm{mL}$ concentration) showed higher DPPH radical-scavenging activity $(80.11 \%)$ than the water extract $(74.65 \%)$. There was also a significant difference in the SOD radical-scavenging activity between ethanol extract and water extract in the same manner as the DPPH radical-scavenging activity [9]. However, this indicates a slight difference, and we concluded that this distinction may come from the difference in the extraction ratio and solvent concentration. Therefore, the 


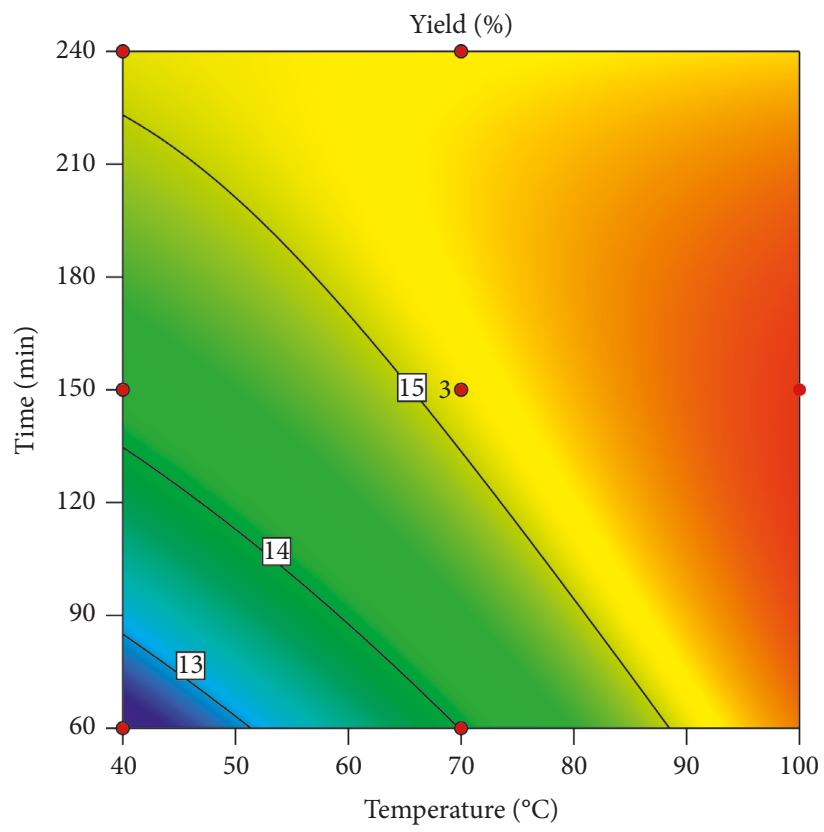

Figure 6: Contour plot for the yield $\left(\%, Y_{1}\right)$ of the turmeric leaf extract at a constant value comparing extraction temperature $\left({ }^{\circ} \mathrm{C}, X_{1}\right)$ and time ( $\min , X_{2}$ ).

TABLE 2: Analysis of variance for the response surface model of extraction yield (\%).

\begin{tabular}{|c|c|c|c|c|c|}
\hline & DF & Adj. SS & Adj. MS & $F$ value & $P$ value \\
\hline Regression & 5 & 9.65475 & 1.93095 & 87.21 & 0.001 \\
\hline Linear & 2 & 6.66667 & 3.33333 & 150.55 & 0.001 \\
\hline Temperature $\left({ }^{\circ} \mathrm{C}\right)$ & 1 & 4.50667 & 4.50667 & 203.55 & 0.001 \\
\hline Time (min) & 1 & 2.16000 & 2.16000 & 97.56 & 0.001 \\
\hline Square & 2 & 0.73809 & 0.36904 & 16.67 & 0.006 \\
\hline Temperature $\left({ }^{\circ} \mathrm{C}\right) *$ temperature $\left({ }^{\circ} \mathrm{C}\right)$ & 1 & 0.06412 & 0.00063 & 0.03 & 0.872 \\
\hline Time $(\min ) *$ time $(\min )$ & 1 & 0.67396 & 0.67396 & 30.44 & 0.003 \\
\hline Interaction & 1 & 2.25000 & 2.25000 & 106.62 & 0.001 \\
\hline Temperature $\left({ }^{\circ} \mathrm{C}\right) *$ time $(\min )$ & 1 & 2.25000 & 2.25000 & 106.62 & 0.001 \\
\hline Residual error & 5 & 0.11070 & 0.02214 & & \\
\hline Lack of fit & 3 & 0.08404 & 0.02801 & 2.10 & 0.339 \\
\hline Pure error & 2 & 0.02667 & 0.01333 & & \\
\hline Total & 10 & 9.76545 & & & \\
\hline
\end{tabular}

TABle 3: Proximate composition content (g/100g) of turmeric leaves and the turmeric leaf extract.

\begin{tabular}{lcc}
\hline & $\begin{array}{c}\text { Dried turmeric } \\
\text { leaves }\end{array}$ & $\begin{array}{c}\text { Turmeric leaf } \\
\text { extract }\end{array}$ \\
\hline $\begin{array}{l}\text { Carbohydrate } \\
\text { g/100 g) }\end{array}$ & 43.3 & 2.6 \\
$\begin{array}{l}\text { Crude protein } \\
\text { (g/100 g) }\end{array}$ & 6.0 & 1.2 \\
Crude fat $(\mathrm{g} / 100 \mathrm{~g})$ & 0.5 & 0.3 \\
Crude ash $(\mathrm{g} / 100 \mathrm{~g})$ & 9.4 & 3.7 \\
Total fiber $(\mathrm{g} / 100 \mathrm{~g})$ & 34.5 & 1.2 \\
Moisture $(\mathrm{g} / 100 \mathrm{~g})$ & 6.3 & 91.0 \\
\hline
\end{tabular}

extraction methods should be set up according to the use purpose. From these results, we confirmed the functionality of byproduct turmeric leaves as a high value-added food source.
The optimum yield of the turmeric leaf extract from central composite design (CCD) was $15.57 \%$ with $150 \mathrm{~min}$ (time) and $1: 25$ (ratio) at $85^{\circ} \mathrm{C}$ (temperature). In addition, proximate composition of turmeric root and dried turmeric leaves was measured to provide background information of them. The proximate composition per dried turmeric leaves $100 \mathrm{~g}$ was $43.3 \mathrm{~g}$ carbohydrate, $6.0 \mathrm{~g}$ crude protein, $0.5 \mathrm{~g}$ crude fat, $9.4 \mathrm{~g}$ crude ash, $34.5 \mathrm{~g}$ total fiber, and $6.3 \mathrm{~g}$ moisture [21]. Comparing this result with that of fresh turmeric leaves shown in Tatianne Ferreira de Oliveira's study [19] were $44.75 \pm 1.04 \mathrm{~g}$ carbohydrates, $39.5 \pm 0.91 \mathrm{~g}$ crude protein, $2.47 \pm 0.12 \mathrm{~g}$ lipids, $13.81 \pm 1.05 \mathrm{~g}$ ash, $34.47 \pm 0.98 \mathrm{~g}$ total fiber, and $6.52 \pm 1.01 \mathrm{~g}$ moisture. There is a slight difference of protein content between fresh and dried turmeric leaves. The protein content in fresh turmeric leaves was higher than that of dried turmeric leaves even though moisture content of both leaves was almost same. This is 
considered due to the degradation of protein by hot-air drying.

\section{Conclusion}

The result of this paper has its own value as fundamental data and the functional background of turmeric leaves. From the result, this study expects that turmeric leaves can be applied in the food industry based on these data. In addition, in vitro and in vivo experiments to determine the safety background and antioxidant functionality are now required for further research and industrial application. Using these optimal extraction conditions of turmeric leaf extract, this study anticipates to process and develop turmeric leaves as a food source and an alternative in food industry areas.

\section{Data Availability}

The data used to support the findings of this study are included within the article.

\section{Conflicts of Interest}

The authors declare that there are no conflicts of interest with respect to the authorship and/or publication of this article.

\section{Acknowledgments}

This work was supported by the Korea Institute of Planning and Evaluation for Technology in Food, Agriculture and Forestry (IPET) (117078-03) through High Value-Added Food Technology Development Program.

\section{References}

[1] D. H. Kim, "Effects of turmeric (Curcuma longa L.) on the physicochemical characteristics of Kochujang during fermentation," Journal of Applied Biological Chemistry, vol. 56, pp. 101-107, 2013.

[2] D. W. Kim, S. M. Lee, H. S. Woo et al., "Chemical constituents and anti-inflammatory activity of the aerial parts of Curcuma longa," Journal of Functional Foods, vol. 26, pp. 485-493, 2016.

[3] I. Chattopadhyay, K. Biswas, U. Bandyopadhyay, and R. K. Banerjee, "Turmeric and curcumin Biological actions and medicinal applications," Current Science, vol. 87, no. 1, pp. 44-53, 2004.

[4] W. S. Tavares, Y. Akhtar, G. L. P. Gonçalves, J. C. Zanuncio, and M. B. Isman, "Turmeric powder and its derivatives from Curcuma longa rhizomes Insecticidal effects on cabbage looper and the role of synergists," Scientific Reports, vol. 6, p. 34093, 2016.

[5] C. H. Lee, A. Y. Kim, C. W. Pyun, M. Fukushima, and K. H. Han, "Turmeric (Curcuma longa) whole powder reduces accumulation of visceral fat mass and increases hepatic oxidative stress in rats fed a high-fat diet," Food Science and Biotechnology, vol. 23, no. 1, pp. 261-267, 2014.

[6] D. R. Ahn, E. B. Lee, B. J. Kim et al., “Antioxidant and lifespan extending property of quercetin-3-odirhamnoside from Curcuma longa L. In Caenorhabditis elegans," Journal of the Korean Society for Applied Biological Chemistry, vol. 57, no. 6, pp. 709-714, 2014.
[7] M. Rana, S. S. Reddy, P. Maurya et al., "Turmerone enriched standardized Curcuma longa extract alleviates LPS induced inflammation and cytokine production by regulating TLR4IRAK1-ROS-MAPK-NF $\kappa$ B axis," Journal of Functional Foods, vol. 16, pp. 152-163, 2015.

[8] R. Wilken, M. S. Veena, M. B. Wang, and E. S. Srivatsan, "Curcumin A review of anti-cancer properties and therapeutic activity in head and neck squamous cell carcinoma," Molecular Cancer, vol. 10, no. 1, p. 12, 2011.

[9] W. Y. Choi and H. Y. Lee, "Enhancement of antioxidant activities of curcuma longa leaves by ultra high pressure extraction," Korean Journal of Medicinal Crop Science, vol. 22, no. 2, pp. 121-126, 2014.

[10] N. Y. Kim, H. W. Lim, and H. Y. Lee, "Comparison of cosmetical activities of Curcuma longa L. Leaf extracts using different extraction methods," Korean Journal of Medicinal Crop Science, vol. 22, no. 4, pp. 255-261, 2014.

[11] C. L. Pathirana and F. Shahidi, "Optimization of extraction of phenolic compounds from wheat using response surface methodology," Food Chemistry, vol. 93, no. 1, pp. 47-56, 2005.

[12] N. F. Azahar, S. S. A. Gani, and N. F. M. Mokhtar, "Optimization of phenolics and flavonoids extraction conditions of Curcuma Zedoaria leaves using response surface methodology," Chemistry Central Journal, vol. 11, no. 1, 2017.

[13] K. J. Park, J. H. Lim, B. K. Kim et al., "Optimization of extraction conditions to obtain functional components from buckwheat (Fagopyrum esculentum M.) sprouts using response surface methodology," Korean Journal of Food Preservation, vol. 16, pp. 734-741, 2009.

[14] H.-J. Lee, J.-R. Do, J.-H. Kwon, and H.-K. Kim, "Optimization of Corni fructus extracts by response surface methodology," Journal of the Korean Society of Food Science and Nutrition, vol. 41, no. 3, pp. 390-395, 2012.

[15] S. J. Heo, E. J. Park, K. W. Lee, and Y. J. Jeon, "Antioxidant activities of enzymatic extracts from brown seaweeds," Bioresource Technology, vol. 96, pp. 1613-1623, 2005.

[16] S. A. Baba and S. A. Malik, "Determination of total phenolic and flavonoid content, antimicrobial and antioxidant activity of a root extract of Arisaema jacquemontii Blume," Journal of Taibah University Medical Sciences, vol. 9, no. 4, pp. 449-454, 2015.

[17] L. Zheng, M. Zhao, C. Xiao, Q. Zhao, and G. Su, "Practical problems when using ABTS assay to assess the radical-scavenging activity of peptides Importance of controlling reaction pH and time," Food Chemistry, vol. 192, pp. 288-294, 2016.

[18] K. Helrich and AOAC, Official Method of Analysis: AOAC, AOAC, Arlington, VA, USA, 15th edition, 1990.

[19] M. C. Braga, E. C. S. Vieira, and T. F. de Oliveira, "Curcuma longa L. leaves: characterization (bioactive and antinutritional compounds) for use in human food in Brazil," Food Chemistry, vol. 265, pp. 308-315, 2018.

[20] X. Guan, L. Li, J. Liu, and S. Li, "Phytochemical properties, proximate and mineral composition of Curcuma longa Linn. and Zingiber officinale Rosc.: a comparative study," Journal of Scientific Research and Reports, vol. 13, no. 4, pp. 1-7, 2017.

[21] A. A. Taoheed, A. A. Tolulop, A. B. Saidu, O. G. Odewumi, R. M. Sunday, and M. Usman, "Phytochemical properties, proximate and mineral composition of Curcuma longa Linn. And Zingiber officinale Rosc.: a comparative study," Journal of Scientific Research and Reports, vol. 13, no. 4, pp. 1-7, 2017.

[22] Q. D. Do, A. A. Tolulope, P. L. Tran-Nguyen et al., "Effect of extraction solvent on total phenol content, total flavonoid content, and antioxidant activity of Limnophila aromatica," Journal of Food and Drug Analysis, vol. 22, pp. 296-302, 2014. 


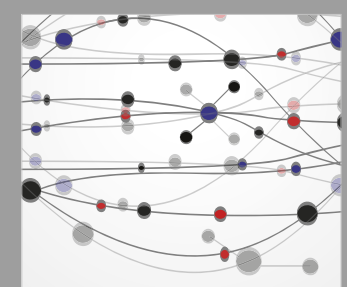

The Scientific World Journal
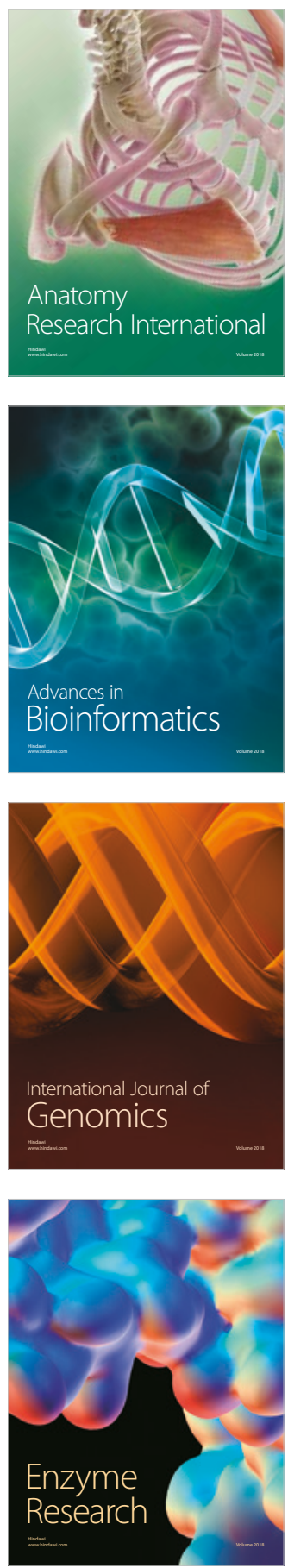
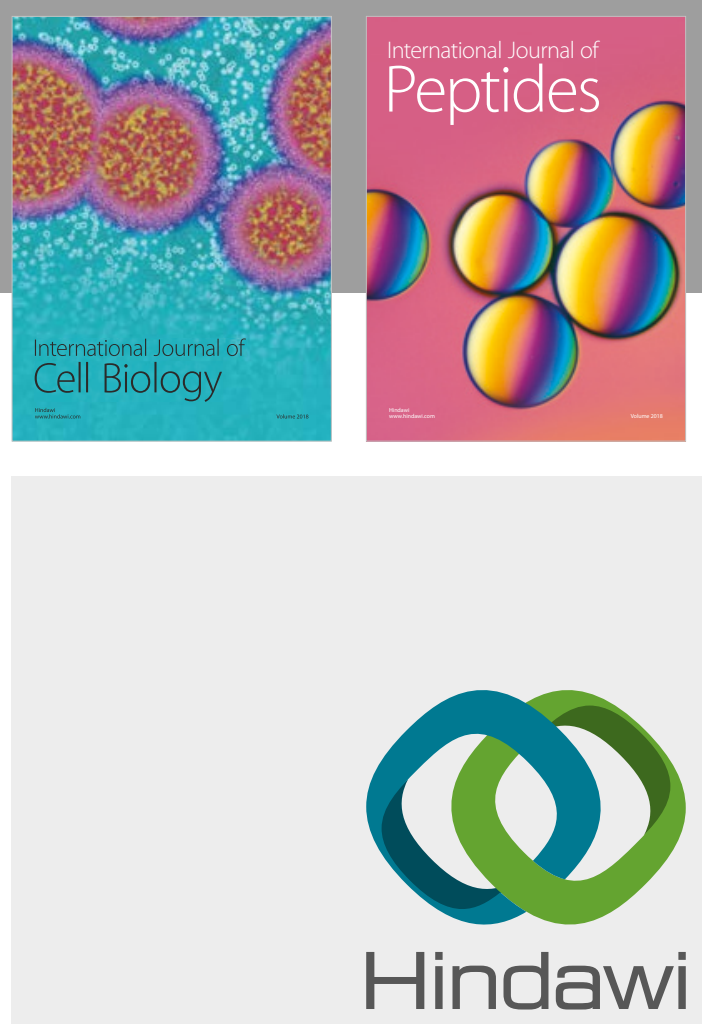

Submit your manuscripts at

www.hindawi.com
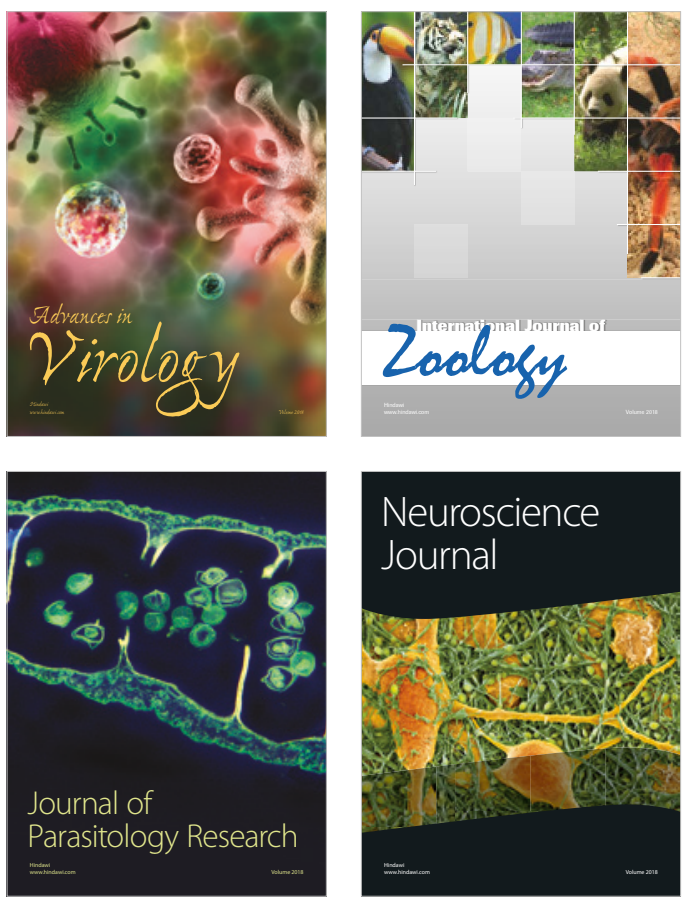
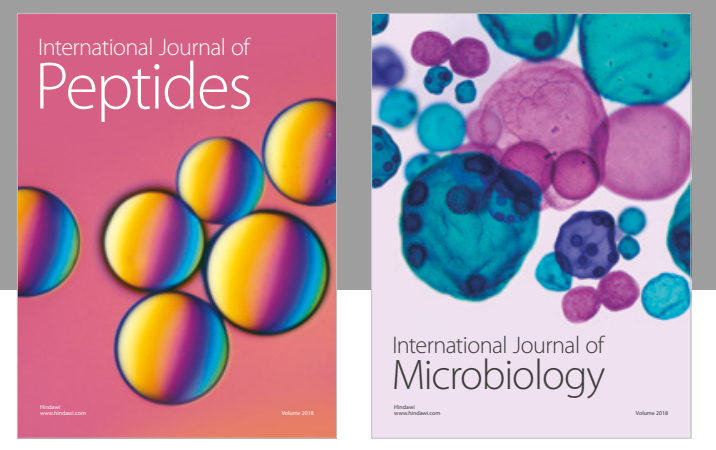

nternational Journal of Microbiology
Journal of
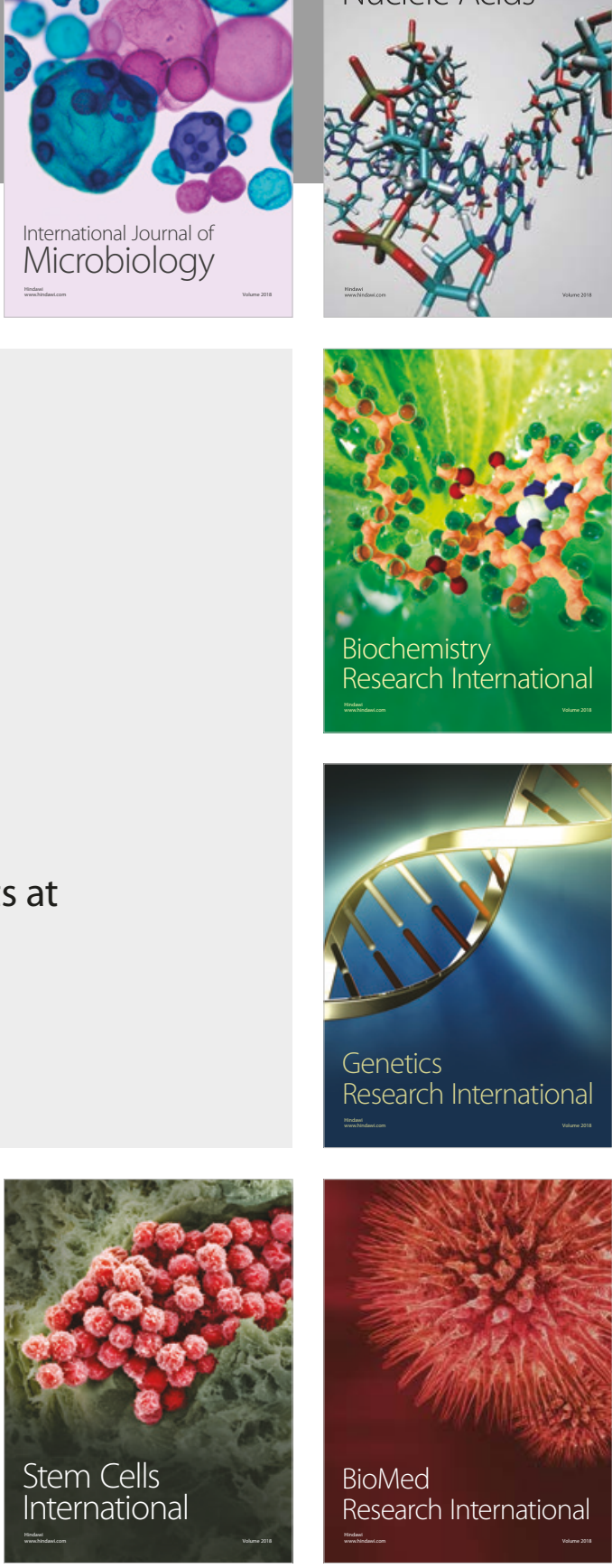
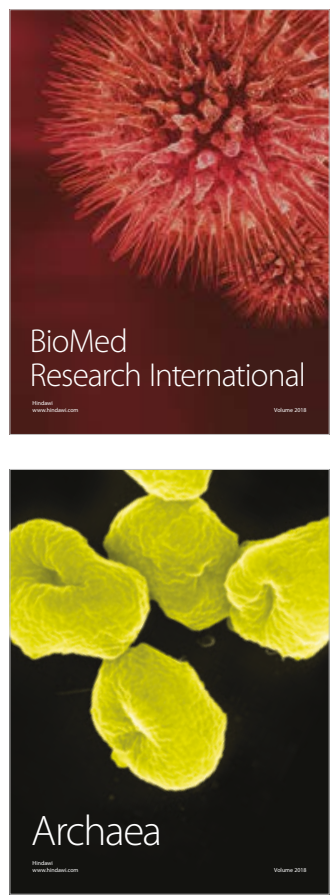